\title{
TRAINING OF PARENTS OF GIFTED AND TALENTED STUDENTS
}

\author{
A. Zlateva*, E. Lavrentsova \\ Faculty of Education, Trakia University, Srtara Zagora, Bulgaria
}

\begin{abstract}
In the paper there are analysed the organisation, conduct and results from training of parents of gifted and talented children as a part of the work for the GATE Project 2013-1-TR1-LEO04-47702. A special attention is paid to providing theoretical and practical help to parents so that they are able to recognize, support and fully help the realization of the gifted child.

Purpose: To give the parents of GAT children the opportunity to get acquainted more closely with the phenomenon of giftedness so as they become able to more easily recognize any manifestations of the gift in their own children, learn about the characteristics of their personality, understand better their difficulties and problems and work with them at home.

Results: The knowledge of what types of characteristics are 'normal' for talented/gifted young people was provided. The difficulties which GAT students encounter at school and at home, were outlined. Main problems with working with gifted children were identified.

Conclusions: In the modern society it's extremely necessary to create tolerance and pro-active format in the parents' attitude towards the problems of their GAT children and to support the parents in the process of constructing maximum favourable conditions for the development of giftedness and creativity in their children.
\end{abstract}

Key words: educating, support, gifted and talented children

\section{INTRODUCTION}

One of the most important objectives of the educational policy of Europe is the use of the intellectual potential of students, which initiates the creation of educational models aimed at the development of every child to the fullest possible range of its individual psychological resources and providing opportunities for its subsequent self-sufficient, enterprising and productive life activities. In these conditions there is a growing interest both in the scientific and theoretical level and the practical aspect of the different types of work with gifted children.

The existence of many layers of the phenomenon of "talent", the consistency and therefore, the complex and multi-dimensional relations between the mental qualities and the abilities of the gifted child require both from the psychologists and the educators, on the one hand and the parents and family environment of a child, on the other, to pay a particular attention to the level of development of the

${ }^{*}$ Correspondence to: Ani Dimova Zlateva, assoc. prof. Trakia University, Faculty of Education, Srtara Zagora,ani_zlateva@yanoo.com child's talent. And if with the study of the manifested, obvious talent the main focus is on its protection and development, in the study of children with potential talent the most acute task is related to its "disclosure" and manifestation.

In the process of spotting out a gifted and talented child and active support for the full development of his or her abilities and talents undoubtedly an especially important role and influence is attributed to the parents, their concerns, interest and attention to the child's problems.

In this connection it's very important to provide theoretical and practical help to parents so that they are able to recognize, support and fully help the realization of the gifted and talented child. Its main purpose is to give the parents of gifted children the opportunity to get acquainted more closely with the actual phenomenon of giftedness so as they become able to more easily recognize any manifestations of the gift in their own children, obtain information about the characteristics of the personality of gifted children, understand better their difficulties and problems, learn about their rights and obligations when raising 
such children, and especially - master advanced ideas and effective approaches to creating maximum favourable conditions for the development of giftedness and creativity in their children.

\section{CONTENT}

The main focus is to present the research of training of parents of gifted and talented children as part of the work of The Lifelong Learning Program Leonardo da Vinci partnership 2013-1-TR1-LEO04-47702 PROJECT "GIFTED AND TALENTED CHILDREN TEACHER'S AND PARENT'S TRAINING" - GATE.

The aim of the training of parents of gifted and talented children was to support them in their work with them at home, in collaboration where possible with teachers and significant others in the educational community.

This support took the form of an interactive half-day workshop. It had been developed from an analysis of Pan-European research and experience into ways parents could best support their children.

The workshop engaged parents with four critical support issues. They are:

Identification \& assessment

This helps parents to know the different ways to identify gifts \& talents in young people. Special emphasis will be given to helping parents of children who show their gifts \& talents in ways that are not always easy to identify with the use of standard abilities tests in school. Children who are divergent thinkers, who have vivid imaginations, whose biggest asset is their creativity or physical abilities.

\section{Social and emotional support}

Rising happy, thriving young people who are working towards being the best they can be, is the ultimate aspiration for most parents and yet sometimes G\&T learners can seem in more need of social and emotional support than other people their age. The workshop explores:

(a) Asynchronous Development

Hypersensitivity (c) Perfectionism.

Supporting a growth mind-set

This engages parents in knowing how to: (a) supports a child to learn and grow from every experience they encounter (b) manage high/unrealistic expectations and (c) avoid experiencing everything as success or failure.

(d) That less than perfect is also acceptable.

Out-of-school support

As a parent, it is often difficult to find interesting, enriching and constructive webbased and out-of-school activities for your G\&T child. In this workshop we illustrate what might be done if your child is talented in sport.
From this we will generalise to help parents find out more about educating, supporting and entertaining their G\&T (1).

- $\quad$ To encourage parents to formulate a personally significant question about parental support for a gifted children.

- $\quad$ To support parents of GAT students to work with them at home, in coherence with teachers and educational community approach.

- $\quad$ To try to answer the questions, 'which person has what kind of gift/talent?'

- To discuss with other parents the many meanings of a 'talented' child.

- To explore different ways to support children with talents (2).

\section{Giftedness: essence and meaning}

In psychology, the term "talent", "giftedness" is used in two main meanings: 1. A peculiar blend of high quality of capabilities, which determines the possibility of achieving success in the implementation of one or other activity; 2. (a narrower sense) anatomical and physiological traits, innate abilities which are genetic prerequisites for the development of abilities, their natural fund. Traditionally, there is a distinction between general or multiple and special talent. At the present stage of development of the pedagogical science, giftedness is mostly seen as a potential for achievements at an extremely high level compared with other people of a given age, education and social environment (3).

Considering the content complexity of the concept of "giftedness", in some educational systems (the British one, for example) it is preferred that the term "highly able" is used, for example, for a student with high abilities. The term "talented" is correspondingly more often used for those children who exhibit high capabilities in the fields of arts and sports.

A gifted child - this is the child who stands out with bright, clear, sometimes extremely high performances (or there are internal prerequisites for such achievements) in one or another activity (4).

There are three categories of gifted children that can be outlined:

1. Children of unusually high general level of mental development, with all other conditions being equal (such children are most often found at preschool and school age);

2. Children with signs of special mental giftedness - in a specific area of science (mainly adolescents);

3. Students who, for one reason or another, have not been successful in training but manifest bright cognitive activity, originality, sound and an extraordinary mental reserves 
(this often occurs in students in the upper level of education).

One of the most popular models of giftedness is "A Developmental Model for Creative Productivity" by Joseph Renzulli. According to Renzulli there is a difference between the terms "school giftedness" and "creative productive giftedness." To clarify the nature of the latter, Renzulli developed a three-circle concept which includes the following key features: ability, dedication and creativity. The term capability here means "above the average general and special abilities" (over $80-85 \%$ ), creativity - the potential for creativity and dedication - very strong motivation for activity in a particular area of life. Creativity is the result of the intersection of the three classes of characteristics of the students. The section in question is the core of the creative talent or the so called "creative potential".

Often there is a tendency to identify intelligence as creativity. But as pointed out by several studies, the relation appears in three varieties: a lack of connection, a partial connection, or a weak correlation. There is the so called category in science "gifted stragglers" ("idiots savants").

In recent years, for a working definition of giftedness and possession of talent, the formula has been accepted which recognizes that the individual can be distinguished by their functional or potential abilities in one or more areas: intellectual, academic (success in training), creative, artistic, in the field of communication or psychomotor performance. Such a wide definition proved extremely useful as a basis for developing the methods for searching and detection of gifted and talented children with physical or sensory deficiencies.

Based on this approach, Gardner describes the following species or types of intelligence, independent of, but interacting with each other: linguistic, logical-mathematical, spatial, musical, bodily-kinaesthetic, interpersonal, intra-personal, naturalistic and existential. Comparing creativity and intelligence, he stated that both involve solving problems and creating products. Creativity, however, includes also an additional category - asking new questions within a domain that are innovative initially, but gradually become accepted in one or more cultural backgrounds. Creativity is distinguished by intelligence in two additional aspects: 1 . the creative person always operates within a discipline or profession and most creative people stand out in one or two at the most domains; 2. what defines the creative act of an individual is the subsequent widespread adoption of innovation. The touchstone is the proven effect on the domain.

The classic IQ tests, designed for "closed tasks," measure mainly the convergent and not the divergent, i.e. creative thinking and its matching creative abilities required for problem solving and creative tasks. Through them usually only the first two types of intelligence are covered and rarely the 3rd type - the spatial intelligence. As for the rest - they remain uncovered.

And precisely here is the special role of the parents, which is to detect one or another kind of intelligence in the child and to put targeted efforts in order to create maximum beneficiary conditions and opportunities for its further development.

\section{Ppersonality of gifted children}

The basic emotional characteristics that are most commonly prevalent in gifted children the scientists determine to be the following:

- Striving for dominance and superiority;

- $\quad$ Striving for taking risks,

- $\quad$ Striving for independence, radicalism and violation of the habitual order.

The following characteristics are also pointed out:

- Optimism;

- Willingness to help;

- $\quad$ A feeling for the beautiful;

- $\quad$ Sense of humour $(5,6,7)$.

Gifted students, especially in the elementary school, demonstrate high performance on the level of involvement in the content of the activity and the level of perfectionism. As far as the peculiarities of the emotional development are concerned, high performance levels of stress-resistance and sustainability of interests can be seen. Their social competence is characterized by openness in social relations and intellectual egocentrism (8).

Some other personality traits that distinguish the gifted, creative children are also noted. These are: recklessness, complacency and not recognizing the social restrictions. It is important to point out that the personality traits of gifted children and adult gifted individuals match. That probably makes the prediction of the existence of creativity in the subject according to his personal peculiarities obvious as early as in childhood. Therefore, it is very important that the parent closely monitors the personality characteristics of the child and be able to capture the relevant personal emotional manifestations of giftedness. 
Often scientists note that creative people have the following characteristics:

1. independence - their standards are more important than the standards of the group, independent assessments and judgments;

2. openness of the mind - willingness to review their own and those of the others fantasies, readiness to accept the new, the unusual;

3 . high tolerance to uncertain and insoluble situations, constructive activity in these situations;

4. a well-developed aesthetic sense.

Other common traits are conscientiousness, responsibility, perseverance, sense of duty, high control over the behaviour and the emotions, determination, enterprise, social courage, intellectual variability. Studies show that connected to creativity are also: taking initiative, confidence, absorption in work, criticism regarding their own and the disadvantages of the others, but also combining such opposites as personal maturity and childish sense of world. Other qualities are: persistence, energy, ambition, forward looking, tolerance for ambiguity, synthetic thinking, insightfulness, thinking in images, clarity, sensitivity, imaginativeness, ability to make associations, intuitiveness, erudition, analytical thinking and ability for concentration.

Some studies show that the level of creativity of teenagers proves statistically associated with such properties of the individual as the ability to take decisions independently, selfconfidence, striving for power and ability to act adequately when in company, tolerance (9). It has been found out that in gifted adolescents aggressiveness is more pronounced. At the same time, the index of hostility has little connection with creativity. This means that aggression in them constitutes a means of selfassertion rather than hostile defensiveness.

But the most common characteristic of giftedness is the pronounced cognitive capability (exhibited as striving for new knowledge, techniques or a way to absorb the activity), which makes up the basis of cognitive motivation, dominant in the gifted child in comparison to other types of motivation (10).

Moreover, several studies have shown that in gifted adolescents there is a distinctive position which consists in the attitude towards life as an open, creative task in which man has to consciously choose values and goals for his or her existence and to seek ways and resources to achieve them. There is a vividly manifested desire to search the meaning of life and a pronounced orientation towards the future. Their distinctive feature is associated with the demonstration of metaphorical ideas about their life.

But at the same time it should be noted that there are certain specifics regarding the personal qualities and emotional and behavioural manifestations in the different categories of gifted children. There is an interesting research performed by Wallach and Kogan (11), showing the dependence of certain personal characteristics of students on the ratio between intellect and creativity. Of the total 4 output groups, three were directly related to gifted children and the following specific differences in their emotional and personal characteristics were identified:

1) Children with a high level of intelligence and creativity are highly socially active (they demonstrated protest against boredom, the deficiencies in the training programs, etc.); a desire to attract attention to themselves was expressed, over aggressiveness, selfconfidence, independence, sociability and popularity among peers. They were able to achieve internal freedom and external control and their behaviour combined maturity and infantile behaviour;

2) Children with low intelligence and high creativity are unpopular among their peers; they feel disadvantaged and often are in constant conflict with their own selves and the surrounding;

3) Highly intelligent children with low creativity (with the so called "schools brilliance") are characterized by selfconfidence, they are popular among their peers and teachers. But they themselves will not seek the society of their peers, do not show social activity and take failures in learning painfully.

Regarding the above differences, it is very important that parents do not fail to recognize the specific personality and psycho-emotional characteristics of their gifted children and to be able to apply the most appropriate educational methods and approaches according to these characteristics.

\section{Difficulties and problems with gifted children}

Scientists note that gifted children have specific needs and thus often face many difficulties and problems. If they are not taken into account, that will not allow the children to realize their potential. Generally, in society and at school, sports and artistic talents are perceived positively, but high intelligence does not produce any serious sympathy. People are annoyed by intellectuals. In this respect, it was found that children with faster mental 
development often try to hide their abilities so as they do not seem "overly smart". Moreover, they often find themselves among the laggards, as they cannot overcome boredom and therefore do not master sufficiently even the necessary basic skills, so they come into conflict with the environment.

A number of studies have established that gifted children, having high, outstripping their peers' level of intellectual abilities, often show some retardation in their physical, social and psycho-emotional development. And this, in turn, raises accompanying difficulties with their social adaptation.

Among the problems of gifted children the most common ones are the following:

1. Hostility towards the school environment due to the fact that the curriculum does not correspond to their abilities;

2. Preference for specific games: gifted children like complex games, they do not show interest in games which their peers with average abilities find attractive;

3. Nonconformity: gifted children tend to reject the standard requirements, especially if those standards are not aligned with their interests;

4. A certain detachment and inclination towards philosophical questions involving phenomena such as death, afterlife, religious belief;

5. Discrepancy between the physical, intellectual and social development: they prefer to play with children of older age and therefore find it difficult to take up leadership positions.

Other scientists, studying the vulnerability of gifted children, outline the following factors:

1. Striving for perfection, which manifests itself very early;

2. Feeling of their own vulnerability: they are exceptionally critical towards their own achievements and hence exhibit a low self-esteem;

3. Being hypersensitive: gifted children tend to be hyperactive and constantly react to different stimuli and incentives;

4. Need for adult attention, that sometimes leads to monopolization, which in turn creates tension with other children;

5. Intolerance in relation to children with a lower level of intellectual development, which can lead to repulsion of their peers.

The main danger that accompanies the lives of gifted children is the fact that their exceptional giftedness often leads to social isolation. Their nonconformist and independent style of communication determines their desire for privacy - a desire which on the one hand reflects the richness of their inner life and on the other - becomes a necessity for the development of their talents. At the same time gifted children seek the support and approval of those around them and may suffer from its eventual lack. Not surprisingly, in comparison with their peers, gifted children, especially girls, admit experiencing great social and emotional difficulties, including low selfesteem and depression.

Due to the above reasons, the opinion that giftedness is not only a gift but also a challenge for the individual is asserting itself among scientists.

Another difficulty, which gifted children often face, is related to their inability to fully realize their creative potential and that consequently results in delinquent behaviour. Various studies indicate that gifted children whose achievements are lower compared to the level of their abilities, experience serious problems in terms of their emotional and personal development, as well as in the field of interpersonal relations. It is in fact that inability to realize their creative potential which appears to be one of the reasons for school disadaptation.

Experience shows that the development of giftedness and talent can be stopped and the sometimes even lost at any stage of individual development. Gifted children are not always the most successful students. They have their own problems and dramas. In the family, they can experience a number of difficulties related to misunderstanding on the part of parents. The latter are worried by the strangeness of their children, their detachment and perseverance, and often demonstrate their clear desire for their children to be like everyone else. At school such children may also be neglected, triggering their teachers' irritation with their extraordinary knowledge and mental abilities. Students who demonstrate special abilities in relatively specialized areas of studies within the mainstream school in many cases remain misunderstood. Educators and parents alike tend to attribute such inconsistency in motivation and intelligence to a child's fault or whim of character.

According to Torrance, gifted and highly able children comprise about $30 \%$ of students dropping out of school because of low achievement scores. Studies by Guilford indicate that, by the end of their school education gifted and talented children experience severe conditions of depression and are forced to disguise their brilliance to hide it from their peers and adults. Other studies show 
that the suicide rate among gifted children is 2.5 times higher than among their peers.

This requires special support from the parents (besides expert psychological and pedagogical help) for the development of a talented and gifted individual.

\section{Proactive Parenting}

The possibility of achieving remarkable results is determined not only by giftedness, inborn abilities and motivational factors, but also by the conditions contributing to the full manifestation of talents and the realization of one's creative potential. Talent development requires appropriate family environment, the lack of which may destroy it.

The fact that the development of creativity requires a supportive environment including the parents is evident in several studies. In analysing biographies of gifted children and prosperous adults it is often noted that their family have focused on their interests and needs - the parents have been attentive and cordial, providing a stimulating environment at home and actively encouraging the development their children's abilities.

A number of studies show that children who are gifted in mathematics, chess, music, etc. have lived in a family environment that is conducive to the advancement of their talents and that their parents have supported them through encouragement and praises $(12,13)$. Divergent thinking is characteristic for those children whose parents have encouraged their intellectual curiosity, stimulated their intellectual activity and provided them with considerable freedom to choose their interests without preventing the expression of their true individual characteristics.

It is extremely important for parents to be able to quickly recognize the talents of their children and contribute to their development.

A high level of creativity is observed in children with a broad range of communication and democratic mother-child relationship. This testifies to the significant role of the conditions of one's life as well as the personal resources in the development of giftedness and creativity.

Scientists emphasize that providing the child with a relative independence, freedom, respectful attitude and lack of excessive strictness outlines the range of conditions in the family which favor the development of giftedness. What is also important is paying increased attention to the abilities of the child and showing sincere interest and involvement in his/her creative self-disclosure. Moreover, families where on the one hand attention is focused on the child and, on the other hand, there is little external control on the child's behaviour, where creativity runs in the family and where unconventional thinking and nonstereotypical action are encouraged, children's abilities and talents are brought forth.

Other factors contributing to creativity have been pointed out:

1. broad range of communication, including adults with artistic abilities;

2. surrounding environment of adults to serve as role models;

3. equality in the relationship between parents and children;

4. providing the child with an opportunity for free emotional self-expression;

5. active, encouraging and supportive position of adults;

6. inclusion to creativity by attending various workshops and extra-curricular activities;

7. inclusion to the joy of knowledge through hands-on experience;

8. positive attitude towards the child's experiential activities.

Using appropriate methods of parental guidance is essential in this respect. Among these methods are:

1. Parents providing a positive example is one of the key educational methods, especially for younger children. It is good if the parents are creative individuals and are able to demonstrate to the child creative behaviour and activity. Every adult has certain areas of knowledge or activities he or she is good at. It is important for the child to see how enthusiastic his or her parents are.

2. Suitable object and spatial environment. In other words, the home environment needs to contribute to the development of the child's creative abilities. Adults should strive constantly to provoke the interest of the child and inspire children to long for creativity.

3. Collegial and democratic style of communication. Collegiality and democracy in communicating with the child create conditions that are extremely important for the formation and development of creative abilities. On the contrary, the authoritarian educational approach will produce obedient and disciplined workers rather than creative personalities. As properly noted by the famous philosopher John Locke slavish discipline generates slave character (14).

4. Reducing conformity. Interacting with the child, the parent should be careful making the distinction between useful, creative imitation versus non-critical copying and unconditional acceptance of the general opinion or position. 
5. Support and development of the child's autonomy and independence. Ability to think, decide and act individually and take responsibility for his or her own actions - these are the characteristics of creative behaviour which are nurtured mostly in the family.

6. Stimulating curiosity and the asking of unusual questions. Parents should not be afraid of such questions, on the contrary, they need to stimulate this process since the question is an expression of the child's interest and an evidence for what seems to be an unconventional and extraordinary view of the world.

\section{RESULTS}

Gaining knowledge of what type of characteristics are 'normal' for talented/gifted young people. Discussion of the surrounding situation of GAT children in Bulgaria. The problems which GAT students encounter at school and at home. Main problems with working with gifted children at home were identified. Creating tolerance in the parents' attitude towards the problems appearing in the intellectual and physiological development of their GAT children. Educating parents about the early manifestation of talents in different areas of knowledge and art, when it comes to GAT children. Discussions about the support with finding, developing, and supporting a talented kid.

Analysis of evaluation questionnaires results after training of parents of gifted and talented children shows that more than $90 \%$ of parents think that workshop achieved its aim, for more than $75 \%$ the workshop completely fulfilled their expectations. Very interesting is to mark that more of $90 \%$ think their understanding and attitude towards GAT students has changed after workshop training. The percentage of parents who think their behaviour towards GAT students might change after the workshop is the same. (cart 1)

In the registration form for the workshop nearly $100 \%$ of the participants noted they think it would be useful to form a local GAT Student Support Group. Some of them said:

"This group would be a great start for the growing-up gifted and talented kids, directing them to follow their inner desires, which are crucial for their inner satisfaction."

"It will help to develop of their potential, giftedness and talents."

"Very often children's giftedness and talent are found at school conditions but they didn't develop. This is the reason it is necessary to form local GAT Student Support Group."

"It will be useful for parents, teachers, psychologists."

"My attitude towards gifted and talented children didn't change after the workshop because it always has been positive, and I always realised that they have special needs. The workshop helped me understand how to satisfy these needs of the talented child, even if the child itself doesn't realize it is in a possession of such a talent.

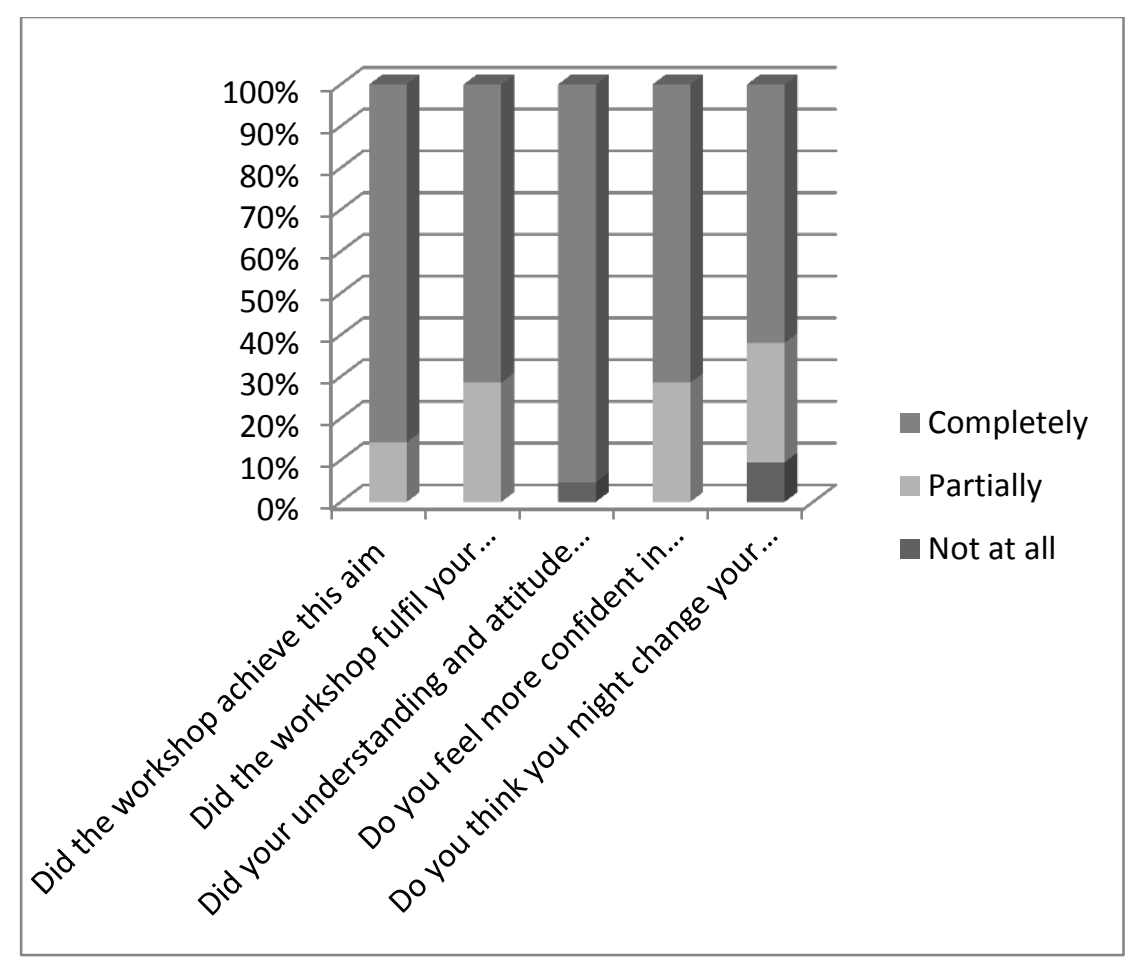

Cart 1. 


\section{CONCLUSION}

In conclusion as result of our work of training of parents of gifted and talented children we can note our conviction about necessity of organizing this kind of training.

This training how we see help parents to learn about:

What is giftedness?. And the special role of the parents, which is to detect one or another kind of intelligence in the child and to put targeted efforts in order to create maximum beneficiary conditions and opportunities for its further development.

Features of the personality of gifted children. It is very important that parents do not fail to recognize the specific personality and psychoemotional characteristics of their gifted children and to be able to apply the most appropriate educational methods and approaches according to these characteristics. Difficulties and problems with gifted children. To help parents to understand that giftedness is not only a gift but also a challenge for the individual is asserting itself among scientists.

Proactive parenting for awakening and developing the creative potential of the child. In the training course parents realized that divergent thinking is characteristic for those children whose parents have encouraged their intellectual curiosity, stimulated their intellectual activity and provided them with considerable freedom to choose their interests without preventing the expression of their true individual characteristics.

On the other side is important a feedback that we have to learn about problems and difficulties that parents of gifted and talented children have with them. To discuss of the surrounding situation of GAT children in Bulgaria. To speak about the problems which GAT students encounter at school and at home. The main problems with working with gifted children at home were identified.

\section{REFERENCES}

1. Booklet for teachers and students of gifted and talented students: Approach to vocational educational training, Leonardo da Vinci partnership, 2013-1-TR1-LEO0447702, project "Gifted and Talented
Children Teachers' and Parents' training" GATE/4.2.)

2. Guidelines to design and to facilitate training activities for teachers and parents of GAT students, Leonardo da Vinci partnership, 2013-1-TR1-LEO04-47702, project "Gifted and Talented Children Teachers' and Parents' training" GATE/4.2.)

3. Aksyonova, E. A., Innovative approaches to education of gifted children abroad // Internet-journal "Eidos", http://www.eidos.ru/journal/2007/01159.htm.

4. Panov, V. I., Giftedness as a problem of modern education: Psychology of consciousness: the current state and problems. Proceeding of the I All-Russian Conference. Samara, 2007. P. 472-484.

5. Barron, F., The disposition toward originality. P. E. Vernon (ed.). Creativity. L. 1972. P. 273-288.

6. MacKinnon, D. W., The personality correlates of creativity: A study of American architects. P. E. Vernon (ed.). Creativity, L. 1972. P. 289-311.

7. Torrance, E. P., Guiding creative talent. Englewood Cloffs. NY. Prentice-Hall. 1962.

8. Myakisheva, N. M, Personality characteristics of intellectually gifted junior school: Proceedings of the IV All-Russian Congress of the Russian Psychological Society. M., 2007. V. 2. P. 351.

9. Soldatova, E. A., Creativity in the personality structure: $\mathrm{PhD}$ thesis abstract. СПб.,1996.

10.Ilyin, E.P., Psychology of creation, creativity and giftedness, Peter Press, St. Petersburg., 2009, P. 216.

11.Wallach, M. A., Kogan, N. A., A new look at the creativity - intelligence Distinction. Journal of Personality. 1965. V. 33. P. 348369.

12.Feldman, D. H., Goldsmith, L. T., Natures gambit. NY. Teachers College Press. 1991.

13.Monass, J. A., Engelhard, J. A. Jr., Home environment and the competitiveness of accomplished individuals in four talent fields. Developmental Psychology. 1990. V. 26. P. 264-268.

14.Doubasenyuk, A.A., Strategies for Gifted Education. Gifted child. 2011. № 2. P. 8592. 